\title{
Animal Models for Periodontal Disease
}

\author{
Helieh S. Oz ${ }^{1}$ and David A. Puleo ${ }^{2}$ \\ ${ }^{1}$ Center for Oral Health Research, College of Dentistry, University of Kentucky Medical Center, Lexington, KY 40536, USA \\ ${ }^{2}$ Center for Biomedical Engineering, University of Kentucky, Lexington, KY 40506, USA \\ Correspondence should be addressed to Helieh S.Oz, helieh.oz@uky.edu
}

Received 5 October 2010; Accepted 12 January 2011

Academic Editor: Oreste Gualillo

Copyright ( $) 2011$ H. S. Oz and D. A. Puleo. This is an open access article distributed under the Creative Commons Attribution License, which permits unrestricted use, distribution, and reproduction in any medium, provided the original work is properly cited.

\begin{abstract}
Animal models and cell cultures have contributed new knowledge in biological sciences, including periodontology. Although cultured cells can be used to study physiological processes that occur during the pathogenesis of periodontitis, the complex host response fundamentally responsible for this disease cannot be reproduced in vitro. Among the animal kingdom, rodents, rabbits, pigs, dogs, and nonhuman primates have been used to model human periodontitis, each with advantages and disadvantages. Periodontitis commonly has been induced by placing a bacterial plaque retentive ligature in the gingival sulcus around the molar teeth. In addition, alveolar bone loss has been induced by inoculation or injection of human oral bacteria (e.g., Porphyromonas gingivalis) in different animal models. While animal models have provided a wide range of important data, it is sometimes difficult to determine whether the findings are applicable to humans. In addition, variability in host responses to bacterial infection among individuals contributes significantly to the expression of periodontal diseases. A practical and highly reproducible model that truly mimics the natural pathogenesis of human periodontal disease has yet to be developed.
\end{abstract}

\section{Introduction}

1.1. Periodontitis. Periodontitis is a highly prevalent, chronic immunoinflammatory disease of the periodontium that results in progressive loss of gingival tissue, the periodontal ligament, and adjacent supporting alveolar bone [1]. In addition to its significant impact on human health, the annual cost of periodontal therapy is estimated to exceed \$14 billion in the USA [2]. Furthermore, periodontitis has been associated with systemic diseases, such as cardiovascular complications [3], rheumatoid arthritis [4], and adverse pregnancy outcomes [5].

Chronic inflammation of the periodontium is initiated by complex subgingival biofilms containing several likely periodontal pathogens. The biofilm generally contains a portion of the gram (-) negative anaerobic commensal microbiota as well as opportunistic pathogens of the oral cavity, including Porphyromonas gingivalis (P. gingivalis) [6]. In response to periodontal pathogens, polymorphonuclear cells (PMNs) release destructive reactive oxygen species (ROS), for example, superoxide, via the respiratory burst [7-9], proteinases, and other factors that can damage host tissues [10-12]. These molecules induce further oxidative damage to gingival tissue, periodontal ligaments, and elicit osteoclastic bone resorption [10, 13-15]. The secreted agents also enhance the production of numerous proinflammatory cytokines that contribute to the disease, including interleukin (IL)-1ß, IL-6, and tumor necrosis factor (TNF $\alpha$ ), among a broad array of biomolecules that have consistently been reported to be elevated in gingival crevicular fluid (GCF) and tissues of periodontitis patients [16-18], rhesus monkeys [19], and dogs [20]. Levels of these proinflammatory molecules are frequently reduced following periodontal therapy $[21,22]$.

Because individuals are not equally susceptible to the destructive effects of periodontal infections, periodontitis is not only caused by bacterial infection but also may be associated with host susceptibility $[23,24]$. Variability in host responses among individuals contributes significantly to the expression of periodontal diseases [24]. Although human cell cultures were found to be useful models for replicating some aspects of the periodontal disease process at the cellular level, information about the complex host response was not prominent [25]. Thus, research into the host response using animals is critically important in the analysis of periodontal disease and development of improved treatments. 
1.2. Animal Models. Animal models have contributed to the generation of new knowledge in biological sciences, including periodontology [19, 20, 26-29]. Periodontal disease can occur naturally or be experimentally induced in animals. Various species have been used to study the pathogenesis of periodontitis and to assess therapeutic modalities against the disease. While animal models have provided a large amount of data, it is sometimes difficult to determine whether the findings are applicable to humans. Thus, a simple and reproducible model that truly mimics human pathogenesis of periodontal disease has yet to be discovered. This paper reviews naturally and experimentally induced animal models used to study different aspects of periodontal diseases.

1.3. Nonhuman Primates. Nonhuman primates have oral structures and teeth similar to those of humans and have naturally occurring dental plaque, calculus, oral microbial pathogens (e.g., P. gingivalis), and periodontal disease. In particular, rhesus monkeys (Macaca mulatta), cynomolgus monkeys (Macaca fascicularis), and baboons (Papio anubis) are susceptible to naturally occurring periodontal disease [30]. To accelerate periodontitis, however, plaqueaccumulating devices, such as orthodontic elastic ligatures or sutures, are commonly placed apical to the interproximal region around selected molars to promote plaque formation [31]. Ligatures are changed at 1-2-week intervals until periodontal pocket formation is confirmed by probing [3236]. The use of nonhuman primates was later modified to include inoculation with human pathogens. Cynomolgus monkeys with no previously detectible human pathogen $P$. gingivalis were treated with the organism. About 5 months later, infection by $P$. gingivalis was confirmed and plaque formation leading to bone loss was observed [26].

Although periodontitis in primates most closely resembles the human disease, the expense of and special husbandry requirements for these animals limit their use in periodontal studies. In addition, they are prone to infectious diseases such as tuberculosis [30], which makes them a less practical model for periodontal diseases.

1.4. Miniature Pigs. Miniature pigs have oral and maxillofacial structures similar to those of humans in terms of anatomy, physiology, and disease development [37]. The Minnesota miniature pig (minipig) was developed about 60 years ago [38] and has been used extensively in biomedical research [39]. After the age of 6 months, minipigs usually develop gingivitis, manifested by inflamed gingival tissue, accumulated plaque and calculus, and bleeding when probed [37]. There is infiltration of inflammatory cells in the gingival tissue that results in progression to severe periodontal inflammation at 16 months of age with identical histopathology to that seen in humans. Periodontitis in minipigs is promoted in about 4-8 weeks using ligatures, and in association with bacterial inoculations of P. gingivalis, S. mutans, and A. actinomycetemcomitans [37]. Minipigs can be suitable for periodontal as well as orofacial investigations. However, minipigs are relatively expensive, with husbandry issues and few studies to support their use.
1.5. Dogs. Dogs provide an appropriate model to study naturally occurring gingivitis and periodontitis [20]. In dogs, the subgingival plaque involves predominantly anaerobic gram $(-)$ negative cocci and rods, $P$. gingivalis and F. nucleatum, similar to human bacteria $[40,41]$. The severity of the disease increases with age and frequently results in loss of tooth. Susceptibility or resistance to periodontal disease in different breeds is mainly dictated by genetic variations [42] rather than the diet [43]. In addition, dogs are used for surgical manipulations, including wound healing and regeneration in periodontal pockets [44].

As a limitation of the natural periodontal diseases, the extent and localization of periodontal lesions are not always synchronized in dogs $[45,46]$. In dogs, the complete width of marginal gingiva is also affected rather than only the tissue lateral to the gingival pocket wall. In addition, animal care regulations, including daily companionship, exercise, space, and maintenance, make use of dogs less desirable in periodontal studies.

1.6. Rodent Models. Rodents provide some unique characteristics to evaluate microbial and host responses to complement primate and human periodontal studies. Rodents have only one incisor and 3 molars in each quadrant. Studies using rodents have elicited disease via placement of ligatures in the gingival sulcus around the molar teeth by increasing biofilm accumulation, as well as disrupting the gingival epithelium, enhancing osteoclastogenesis and bone loss [29]. In alternative models, these animals are orally infected with select human pathogens, attempting to document the virulence of these species in rodents $[9,47]$. These approaches have also enabled the use of genetically manipulated strains to focus on individual components of the host response and to thereby describe their role in the disease process $[48,49]$. More recently, different investigators have used gingival tissue inoculated with chemicals $[28,50]$, microorganisms [51], or their products $[52,53]$ to elicit periodontal disease.

1.6.1. Rats. Rats are often used in models of experimental periodontitis because periodontal anatomy in the molar region shares some similarities with that of humans. Furthermore, rats are easy to handle and can be obtained with different genomes and microbial status. There is clear evidence from the literature demonstrating horizontal bone loss in rats infected with Aggregatibacter (Actinobacillus) actinomycetemcomitans [54-59] or P. gingivalis [56-60]. Periodontitis has been induced in rats by placing a bacterial plaque retentive silk or cotton ligature in the gingival sulcus around the molar teeth [61]. In addition, alveolar bone loss has been induced by the injection of $P$. gingivalis [62].

Rice Rats. The swamp rice rat, or rice rat (Oryzomys palustris), is a native American species found wildly in the southern US [63]. These animals are highly susceptible to periodontal disease, beginning as early as 2 weeks of age [64]. The gingival tissues become swollen, with pocket formation, accumulation of debris, and ulceration at about 3 months 
of age. Alveolar bone resorption underneath the gingiva causes the teeth to slide apart and eventually to exfoliate. Heavy plaque formation occurs more on mandibular than on maxillary teeth. Calculus and root-surface caries frequently occur in older animals. The incidence of periodontal disease has been shown to depend upon dietary factors $[64,65]$. A soft-powder diet with high-carbohydrate content is required for the initiation of the disease in younger animals [64, 65 ], while high fat or protein diets reduced the severity of disease [66]. Periodontitis in rice rats can be transmitted by coprophagy $[66,67]$. Early pathological findings include an acute inflammatory response, with polymorphonuclear cells infiltrating beneath the junctional and crevicular epithelium and into the gingival sulcus, followed by "activated" macrophages infiltrating into the affected epithelium. The connective tissues are destroyed, and the epithelial attachment migrates apically along the root surface, deepening the pocket [63]. The advanced lesions present as a destruction of the alveolar bone with fibrosis and granulation of the gingival connective tissues and periodontal ligament space. Gram (+) positive bacteria, S. sanguis, Actinomyces, and Lactobacilli have been isolated at 5-9 weeks of age from the oral cavity [68]. Unlike the chronic process in human periodontitis, which takes many years, in the rice rat the disease progresses to a chronic destruction of soft and hard tissue within a few weeks. Rice rats have been used to evaluate the dietary effects and some therapeutic modalities.

\subsubsection{Mice}

Baker Mouse Model. The Baker mouse model of periodontitis has been used to measure alveolar bone resorption caused by oral bacterial inoculums as an outcome for the clinical presentation of periodontitis in humans [69]. To assess the virulence of periodontal pathogens, specific pathogen-free female BALB/c mice (10 weeks old) were orally infected with strains of A. actinomycetemcomitans and/or P. gingivalis [70-72]. Prior to infection, mice were given antibiotics (sulfamethoxazole and trimethoprim) in their water for about 10 days to suppress the normal oral microflora. Mice were treated by oral gavage five times at 2-day intervals with one type or an admixture of bacteria resuspended in carboxymethylcellulose to establish the infection. Alveolar bone loss was detected after 10 weeks. It was speculated that $P$. gingivalis initiated experimental periodontitis, at least in part, by modifying the endogenous subgingival biofilm to acquire enhanced virulence [73]. Mice naturally develop periodontitis starting at about 9 months of age with further increases as a function of age, similar to human periodontitis. This model, however, may not reproduce all aspects of human periodontitis initiation and progression; the bacteria used are one or two of at least 150 microbial types present in any dental plaque biofilm. However mice can be utilized to understand the host-parasite interaction [74]. Young mice also can develop periodontitis caused by their own flora, if their ability to control their indigenous bacteria is compromised by genetic defects in their phagocytes, although the presence of antibiotics prevents the development of the disease [75].

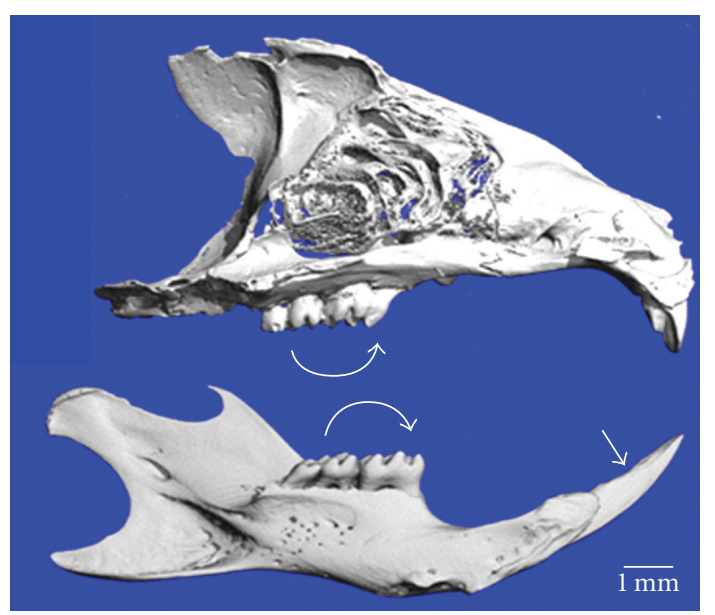

FIgure 1: Micro CT images of mouse maxilla (top) and mandible (bottom) show 3 molars (curved arrow) and single incisor (arrowhead). Courtesy of HS. Oz and DA. Puleo (unpublished data).

Chemically Induced Mouse Model. An alternative method for inducing inflammation of oral tissues is by using trinitrobenzene sulfonic acid (TNBS) or dextran sulphate sodium (DSS) $[28,50]$. These chemicals are often utilized to induce acute ( 1 cycle) and chronic inflammation $(3-5$ cycles) in the gut to evaluate progression of inflammatory bowel disease (IBD) [76-79]. TNBS delivered rectally and DSS provided orally elicit gastrointestinal inflammation, linked with the natural microbiota of the murine gut [80-82]. DSS acts to undermine the epithelial barrier and is an immune cell activator, resulting in innate immune damage to the tissues. TNBS appears to function as a hapten to modify autologous proteins and induce a T-cell-mediated response, resulting in autoimmune-like inflammatory responses [83]. In addition, these compounds upregulate ROS to create a reproducible model of IBD [76-83]. Oral delivery of DSS or TNBS for an extended period of 18 weeks resulted in chronic oral mucosal inflammation and alveolar bone loss $[26,50]$. Mice treated biweekly with DSS in their diet developed systemic disease manifestations, including diarrhea and colitis and dysregulated hepatic concentrations of antioxidants in a time-dependent manner that correlated with a significant increase in alveolar bone resorption.Mice treated orally with TNBS 2 times/week developed no systemic clinical symptoms $[28,50]$. Oral administration of TNBS resulted in a localized action on periodontal tissues with alveolar bone loss observed in both maxilla and mandibles with progression in a time-dependent manner. In contrast, TNBS injection into gingival tissues caused a localized but severe and acute infiltration of inflammatory cells, granuloma formation, and rapid and extensive alveolar bone loss. Implementation of these inflammatory bone resorption models will enable determination of ROS contributions to inflammatory disease lesions in the oral cavity $[28,50]$. Mice have 3 molars and 1 rootless incisor in each quadrant (Figure 1) and provide minute amount of gingival tissue. Therefore, relatively large numbers of animals per group are needed. 
TABLE 1: Advantages and disadvantages of select animal models for studying periodontal disease development.

\begin{tabular}{|c|c|c|}
\hline Animal model & Advantages & Disadvantages \\
\hline Nonhuman primates & $\begin{array}{l}\text { Similar dental structure, microflora, and disease } \\
\text { to humans'. Natural or experimentally induced } \\
\text { periodontitis. }\end{array}$ & Very expensive, with ethical and husbandry issues \\
\hline Dogs & $\begin{array}{l}\text { Develop natural or experimental periodontitis } \\
\text { similar to humans }\end{array}$ & $\begin{array}{l}\text { Relatively expensive, need special daily care, } \\
\text { husbandry issues. Dentition different from humans. }\end{array}$ \\
\hline Miniature pigs & $\begin{array}{l}\text { Dental structure and periodontitis have some } \\
\text { similarity to humans. Natural or experimentally } \\
\text { induced periodontitis. }\end{array}$ & $\begin{array}{l}\text { Relatively expensive, husbandry issues; relatively } \\
\text { few studies }\end{array}$ \\
\hline Ferrets & $\begin{array}{l}\text { Naturally or experimentally induced disease } \\
\text { with similarity to humans' }\end{array}$ & Some husbandry issues \\
\hline Rodents & $\begin{array}{l}\text { Experimentally induced disease. Similar molar } \\
\text { structure to humans'. Inexpensive model }\end{array}$ & $\begin{array}{l}\text { Naturally resistant to periodontitis. Different } \\
\text { microbiota from humans'. Small size and therefore } \\
\text { amount of tissue for analysis. Large number of } \\
\text { animals needed }\end{array}$ \\
\hline
\end{tabular}

Murine Incisor Abscess Model. Rodent incisors have no roots and are continually erupting. To induce a gum pocket abscess model, outbred ICR mice (3-6 weeks old) were injected for 3 days into the gums of lower incisors with $F$. nucleatum that naturally does not colonize mice [84]. The swelling at the site of the injection suggested a short-term F. nucleatum infection. Histological examination using $\mathrm{H} \& \mathrm{E}$ staining showed granuloma formation within the inflamed gum. This model needs repeated injections of the bacteria and has a limited use in studying gum pocket abscess to mimic chronic halitosis caused by microbial infection.

Murine Back Abscess Model. The murine back abscess model has been used to investigate the interactions of both oral microbial species and host responses to various oral pathogens as monomicrobial infections leading to soft tissue destruction (e.g., P. gingivalis [85-87] and Treponema denticola [88]). Mixed infections ( $P$. gingivalis and F. nucleatum [89]; P. gingivalis and A. actinomycetemcomitans [90]) have been shown to result in formation of larger abscess compared to a monoinfection [89]. Coinfection with S. constellatus and F. nucleatum caused death in mice, while monoinfection with these organisms was not lethal [91]. In addition, the mouse subcutaneous chamber model has been used to study hostbacteria interactions and to determine virulence variations among $P$. gingivalis strains leading to tissue damage and invasion [92]. Although, the lesions are not located in the oral cavity, this model has some value for examining bacterially induced infections/coinfections that result in soft tissue destruction.

\subsection{Other Animals}

1.7.1. Horses. Common naturally occurring oral diseases in horses include buccal abrasions, calculus, gingival recession, and periodontal pockets. According a recent equine survey, the prevalence of periodontal pockets and gingival recession is highest in older horses and mostly associated with other dental disorders and tooth loss [93]. Because of their size and husbandry considerations, horses are not a practical model for basic science studies of periodontitis or for testing of potential therapies.

1.7.2. Rabbits. Characterization of the oral microorganisms in rabbits showed numerous pathogenic bacteria, including F. nucleatum, P. heparinolytica, Prevotella spp., P. micros, S. milleri group, A. israelii, and A. haemolyticum, which is somehow consistent with the flora related to periodontal disease in humans [94]. Rabbits have been used for creation of surgically induced periodontal defect and to study periodontal regeneration, but they have been found less suitable for regeneration of periodontal ligament [94, 95].

1.7.3. Ferrets. Ferrets (Mustela putorius) naturally develop calculus and periodontal disease similar to humans [96, 97]. Unlike rodents, calculus formation in ferrets does not depend on the diet and can be scored in live ferrets [96]. Ferrets are a suitable model to study calculus; however, they can easily escape from standard cages and they need special maintenance.

1.7.4. Hamsters. Hamsters have a dental formula similar to that of rats, and they develop experimental periodontitis using ligatures around the molar teeth [98-100]. In addition, hamsters have buccal pouches lined with stratified squamous epithelium that are useful for studying oral carcinoma [101]. The disease development is very similar to rats.

\section{Conclusion}

Each animal model for periodontal disease has advantages and disadvantages (summarized in Table 1). Several show similarities to human disease. While nonhuman primates are most similar to the human condition, their cost and husbandry issues preclude widespread use for both basic science and therapeutic studies of periodontal disease. Rodents are less expensive and easier to handle; however, they do not reproduce all aspects of human periodontitis 
progression. For example, ligatures and/or seeding with exogenous (human) pathogens comprising only one or two from hundreds of microbes that constitute dental plaque biofilm are often needed to induce disease. In addition, rodents have their unique dental anatomical differences. Nonetheless, rats and mice are useful for understanding some aspects of the host-microbe interaction and therapies.

\section{Acknowledgments}

This research was partially supported by grants from National Institutes of Health NIDCR-DE019177 (HO) and National Science Foundation, EPS-0814194 (DP).

\section{References}

[1] B. L. Pihlstrom, B. S. Michalowicz, and N. W. Johnson, "Periodontal diseases," Lancet, vol. 366, no. 9499, pp. 18091820, 2005.

[2] L. J. Brown, B. A. Johns, and T. P. Wall, "The economics of periodontal diseases," Periodontology 2000, vol. 29, no. 1, pp. 223-234, 2002.

[3] M. Desvarieux, R. T. Demmer, T. Rundek et al., "Periodontal microbiota and carotid intima-media thickness: the Oral Infections and Vascular Disease Epidemiology Study (INVEST)," Circulation, vol. 111, no. 5, pp. 576-582, 2005.

[4] P. de Pablo, I. L. Chapple, C. D. Buckley, and T. Dietrich, "Periodontitis in systemic rheumatic diseases," Nature Reviews. Rheumatology, vol. 5, no. 4, pp. 218-224, 2009.

[5] X. Xiong, P. Buekens, W. D. Fraser, J. Beck, and S. Offenbacher, "Periodontal disease and adverse pregnancy outcomes: a systematic review," BJOG, vol. 113, no. 2, pp. 135-143, 2006.

[6] S. C. Holt and J. L. Ebersole, "Porphyromonas gingivalis, Treponema denticola, and Tannerella forsythia: the 'red complex', a prototype polybacterial pathogenic consortium in periodontitis," Periodontology 2000, vol. 38, pp. 72-122, 2005.

[7] I. L. C. Chapple, "Reactive oxygen species and antioxidants in inflammatory diseases," Journal of Clinical Periodontology, vol. 24, no. 5, pp. 287-296, 1997.

[8] I. L. C. Chapple, G. Brock, C. Eftimiadi, and J. B. Matthews, "Glutathione in gingival crevicular fluid and its relation to local antioxidant capacity in periodontal health and disease," Journal of Clinical Pathology: Molecular Pathology, vol. 55, no. 6, pp. 367-373, 2002.

[9] L. Kesavalu, V. Bakthavatchalu, M. M. Rahman et al., "Omega-3 fatty acid regulates inflammatory cytokine/mediator messenger RNA expression in Porphyromonas gingivalisinduced experimental periodontal disease," Oral Microbiology and Immunology, vol. 22, no. 4, pp. 232-239, 2007.

[10] R. J. Waddington, R. Moseley, and G. Embery, "Reactive oxygen species: a potential role in the pathogenesis of periodontal diseases," Oral Diseases, vol. 6, no. 3, pp. 138$151,2000$.

[11] C. O. Enwonwu, "Cellular and molecular effects of malnutrition and their relevance to periodontal diseases," Journal of Clinical Periodontology, vol. 21, no. 10, pp. 643-657, 1994.

[12] C. O. Enwonwu, "Interface of malnutrition and periodontal diseases," American Journal of Clinical Nutrition, vol. 61, no. 2, pp. 430S-436S, 1995.
[13] Y. Kowashi, F. Jaccard, and G. Cimasoni, "Sulcular polymorphonuclear leucocytes and gingival exudate during experimental gingivitis in man," Journal of Periodontal Research, vol. 15, no. 2, pp. 152-158, 1980.

[14] A. Gustafsson, "Increased release of free oxygen radicals from peripheral neutrophils in adult periodontitis after Fc $\gamma$ receptor stimulation," Journal of Clinical Periodontology, vol. 23, no. 1, pp. 38-44, 1996.

[15] L. L. Key Jr., W. C. Wolf, C. M. Gundberg, and W. L. Ries, "Superoxide and bone resorption," Bone, vol. 15, no. 4, pp. 431-436, 1994.

[16] W. A. Bretz, R. J. Weyant, P. M. Corby et al., "Systemic inflammatory markers, periodontal diseases, and periodontal infections in an elderly population," Journal of the American Geriatrics Society, vol. 53, no. 9, pp. 1532-1537, 2005.

[17] J. L. Ebersole and M. A. Taubman, "The protective nature of host responses in periodontal diseases," Periodontology 2000, vol. 5, pp. 112-141, 1994.

[18] G. P. Garlet, W. Martins Jr., B. A. L. Fonseca, B. R. Ferreira, and J. S. Silva, "Matrix metalloproteinases, their physiological inhibitors and osteoclast factors are differentially regulated by the cytokine profile in human periodontal disease," Journal of Clinical Periodontology, vol. 31, no. 8, pp. 671-679, 2004.

[19] K. L. Li, R. Vogel, M. K. Jeffcoat et al., "The effect of ketoprofen creams on periodontal disease in rhesus monkeys," Journal of Periodontal Research, vol. 31, no. 8, pp. 525-532, 1996.

[20] Z. Pavlica, M. Petelin, A. Nemec, D. Erzen, and U. Skaleric, "Measurement of total antioxidant capacity in gingival crevicular fluid and serum in dogs with periodontal disease," American Journal of Veterinary Research, vol. 65, no. 11, pp. 1584-1588, 2004.

[21] C. G. Sharma and A. R. Pradeep, "Gingival crevicular fluid osteopontin levels in periodontal health and disease," Journal of Periodontology, vol. 77, no. 10, pp. 1674-1680, 2006.

[22] E. Ardite, M. Sans, J. Panés, F. J. Romero, J. M. Piqué, and J. C. Fernández-Checa, "Replenishment of glutathione levels improves mucosal function in experimental acute colitis," Laboratory Investigation, vol. 80, no. 5, pp. 735-744, 2000.

[23] G. E. Salvi and N. P. Lang, "Host response modulation in the management of periodontal diseases," Journal of Clinical Periodontology, vol. 32, no. 6, pp. 108-129, 2005.

[24] H. A. Schenkein, "Host responses in maintaining periodontal health and determining periodontal disease," Periodontology 2000, vol. 40, no. 1, pp. 77-93, 2006.

[25] A. Sfakianakis, C. E. Barr, and D. L. Kreutzer, "Actinobacillus actinomycetemcomitans-induced expression of IL- $1 \alpha$ and IL- $1 \beta$ in human gingival epithelial cells: role in IL-8 expression," European Journal of Oral Sciences, vol. 109, no. 6, pp. 393-401, 2001.

[26] S. C. Holt, J. Ebersole, J. Felton, M. Brunsvold, and K. S. Kornman, "Implantation of Bacteroides gingivalis in nonhuman primates initiates progression of periodontitis," Science, vol. 239, no. 4835, pp. 55-57, 1988.

[27] B. Klausen, "Microbiological and immunological aspects of experimental periodontal disease in rats: a review article," Journal of Periodontology, vol. 62, no. 1, pp. 59-73, 1991.

[28] H. S. Oz and J. L. Ebersole, "A novel murine model for chronic inflammatory alveolar bone loss," Journal of Periodontal Research, vol. 45, no. 1, pp. 94-99, 2010.

[29] X. Cai, C. Li, G. Du, and Z. Cao, "Protective effects of baicalin on ligature-induced periodontitis in rats," Journal of Periodontal Research, vol. 43, no. 1, pp. 14-21, 2008. 
[30] S. Schou, P. Holmstrup, and K. S. Kornman, "Non-human primates used in studies of periodontal disease pathogenesis: a review of the literature," Journal of Periodontology, vol. 64, no. 6, pp. 497-508, 1993.

[31] T. E. Madden and J. G. Caton, "Animal models for periodontal disease," Methods in Enzymology, vol. 235, pp. 106-119, 1994.

[32] S. C. Holt, M. Brunsvold, A. Jones, R. Wood, and J. L. Ebersole, "Cell envelope and cell wall immunization of Macaca fascicularis: effect on the progression of ligatureinduced periodontitis," Oral Microbiology and Immunology, vol. 10, no. 6, pp. 321-333, 1995.

[33] J. L. Ebersole, M. Brunsvold, B. Steffensen, R. Wood, and S. C. Holt, "Effects of immunization with Porphyromonas gingivalis and Prevotella intermedia on progression of ligatureinduced periodontitis in the nonhuman primate Macaca fascicularis," Infection and Immunity, vol. 59, no. 10, pp. 3351-3359, 1991.

[34] K. S. Kornman, S. C. Holt, and P. B. Robertson, "The microbiology of ligature-induced periodontitis in the cynomolgus monkey," Journal of Periodontal Research, vol. 16, no. 4, pp. 363-371, 1981.

[35] M. Weinreb, H. Quartuccio, J. G. Seedor et al., "Histomorphometrical analysis of the effects of the bisphosphonate alendronate on bone loss caused by experimental periodontitis in monkeys," Journal of Periodontal Research, vol. 29, no. 1, pp. 35-40, 1994.

[36] G. R. Persson, L. D. Engel, B. J. Moncla, and R. C. Page, "Macaca nemestrina: a non-human primate model for studies of periodontal disease," Journal of Periodontal Research, vol. 28, no. 4, pp. 294-300, 1993.

[37] S. Wang, Y. Liu, D. Fang, and S. Shi, "The miniature pig: a useful large animal model for dental and orofacial research," Oral Diseases, vol. 13, no. 6, pp. 530-537, 2007.

[38] D. C. England, L. M. Winters, and L. E. Carpenter, "The development of a breed of miniature swine; a preliminary report," Growth, vol. 18, no. 4, pp. 207-214, 1954.

[39] I. A. Polejaeva, S. H. Chen, T. D. Vaught et al., "Cloned pigs produced by nuclear transfer from adult somatic cells," Nature, vol. 407, no. 6800, pp. 86-90, 2000.

[40] J. Egelberg, "Local effect of diet on plaque formation and development of gingivitis in dogs. I. Effect of hard and soft diets," Odontologisk Revy, vol. 16, pp. 31-41, 1965.

[41] S. E. Hamp, J. Lindhe, and H. Löe, "Experimental periodontitis in the beagle dog," Journal of Periodontal Research, no. 10, pp. 13-14, 1972.

[42] D. H. Kwon, W. Bennett, S. Herberg et al., "Evaluation of an injectable rhGDF-5/PLGA construct for minimally invasive periodontal regenerative procedures: a histological study in the dog," Journal of Clinical Periodontology, vol. 37, no. 4, pp. 390-397, 2010.

[43] R. C. Page and H. E. Schroeder, "Spontaneous chronic periodontitis in adult dogs. A clinical and histopathological survey," Journal of Periodontology, vol. 52, no. 2, pp. 60-73, 1981.

[44] U. M. Wikesjö, C. J. Kean, and G. J. Zimmerman, "Periodontal repair in dogs: supraalveolar defect models for evaluation of safety and efficacy of periodontal reconstructive therapy," Journal of Periodontology, vol. 65, no. 12, pp. 1151-1157, 1994.

[45] J. M. Haney, G. J. Zimmerman, and U. M. Wikesjö, "Periodontal repair in dogs: evaluation of the natural disease model," Journal of Clinical Periodontology, vol. 22, no. 3, pp. 208-213, 1995.
[46] X. Struillou, H. Boutigny, A. Soueidan, and P. Layrolle, "Experimental animal models in periodontology: a review," The Open Dentistry Journal, vol. 29, pp. 37-47, 2010.

[47] L. Kesavalu, S. Sathishkumar, V. Bakthavatchalu et al., "Rat model of polymicrobial infection, immunity, and alveolar bone resorption in periodontal disease," Infection and Immunity, vol. 75, no. 4, pp. 1704-1712, 2007.

[48] J. J. Yu, M. J. Ruddy, G. C. Wong et al., "An essential role for IL-17 in preventing pathogen-initiated bone destruction: recruitment of neutrophils to inflamed bone requires IL-17 receptor-dependent signals," Blood, vol. 109, no. 9, pp. 37943802, 2007.

[49] J. Alayan, S. Ivanovski, and C. S. Farah, "Alveolar bone loss in T helper 1/T helper 2 cytokine-deficient mice," Journal of Periodontal Research, vol. 42, no. 2, pp. 97-103, 2007.

[50] H. S. Oz, T. Chen, and J. L. Ebersole, "A model for chronic mucosal inflammation in IBD and periodontitis," Digestive Diseases and Sciences, vol. 55, no. 8, pp. 2194-2202, 2010.

[51] K. Nakajima, N. Hamada, Y. Takahashi et al., "Restraint stress enhances alveolar bone loss in an experimental rat model," Journal of Periodontal Research, vol. 41, no. 6, pp. 527-534, 2006.

[52] K. L. Kirkwood, J. A. Cirelli, J. E. Rogers, and W. V. Giannobile, "Novel host response therapeutic approaches to treat periodontal diseases," Periodontology 2000, vol. 43, no. 1, pp. 294-315, 2007.

[53] M. A. Taubman, P. Valverde, X. Han, and T. Kawai, "Immune response: they key to bone resorption in periodontal disease," Journal of Periodontology, vol. 76, no. 11, pp. 2033-2041, 2005.

[54] M. A. Taubman, E. D. Stoufi, G. J. Seymour, D. J. Smith, and J. L. Ebersole, "Immunoregulatory aspects of periodontal disease," Advances in dental research, vol. 2, no. 2, pp. 328333, 1988.

[55] K. Yamashita, J. W. Eastcott, M. A. Taubman, D. J. Smith, and D. S. Cox, "Effect of adoptive transfer of cloned actinobacillus actinomycetemcomitans-specific T helper cells on periodontal disease," Infection and Immunity, vol. 59, no. 4, pp. 1529-1534, 1991.

[56] E. Maki, "Effect of lipopolysaccharide on biological properties and induction of alveolar bone resorption in rats," Aichi Gakuin Daigaku Shigakkai shi, vol. 28, no. 1, pp. 283-294, 1990.

[57] M. A. Taubman, H. Yoshie, J. R. Wetherell Jr., J. L. Ebersole, and D. J. Smith, "Immune response and periodontal bone loss in germfree rats immunized and infected with Actinobacillus actinomycetemcomitans," Journal of Periodontal Research, vol. 18, no. 4, pp. 393-401, 1983.

[58] C. H. Roeterink, T. J. M. Van Steenbergen, W. F. B. De Jong, and J. De Graaff, "Histopathological effects in the palate of the rat induced by injection with different black-pigmented Bacteroides strains," Journal of Periodontal Research, vol. 19, no. 3, pp. 292-302, 1984.

[59] R. T. Evans, B. Klausen, N. S. Ramamurthy, L. M. Golub, C. Sfintescu, and R. J. Genco, "Periodontopathic potential of two strains of Porphyromonas gingival is in gnotobiotic rats," Archives of Oral Biology, vol. 37, no. 10, pp. 813-819, 1992.

[60] B. Klausen, C. Sfintescu, and R. T. Evans, "Asymmetry in periodontal bone loss of gnotobiotic Sprague-Dawley rats," Archives of Oral Biology, vol. 36, no. 9, pp. 685-687, 1991.

[61] T. Breivik, P. K. Opstad, P. Gjermo, and P. S. Thrane, "Effects of hypothalamic-pituitary-adrenal axis reactivity on periodontal tissue destruction in rats," European Journal of Oral Sciences, vol. 108, no. 2, pp. 115-122, 2000. 
[62] K. Nakajima, N. Hamada, Y. Takahashi et al., "Restraint stress enhances alveolar bone loss in an experimental rat model," Journal of Periodontal Research, vol. 41, no. 6, pp. 527-534, 2006.

[63] E. P. Leonard, "Animal model of human disease. Periodontitis," American Journal of Pathology, vol. 96, no. 2, pp. 643646, 1979.

[64] OM. P. Gupta and J. H. Shaw, "Periodontal disease in the rice rat. I. Anatomic and histopathologic findings," Oral Surgery, Oral Medicine, Oral Pathology, vol. 9, no. 6, pp. 592-603, 1956.

[65] J. H. Shaw, "Influence of alternating feedings of diets with high and low potentials to cause periodontal syndrome in rice rats," Journal of Dental Research, vol. 48, no. 3, p. 486, 1969.

[66] J. H. Shaw and D. Griffiths, "Relation of protein, carbohydrate, and fat intake to the periodontal syndrome," Journal of Dental Research, vol. 40, pp. 614-621, 1961.

[67] D. S. Dick and J. H. Shaw, "The infectious and transmissible nature of the periodontal syndrome of the rice rat," Archives of Oral Biology, vol. 11, no. 11, pp. 1095-1108, 1966.

[68] A. Toth, F. M. Beck, E. X. Beck, N. Flaxman, and S. Rosen, "Effect of antimicrobial agents on root surface caries, alveolar bone loss, and microflora in rice rats," Journal of Dental Research, vol. 65, no. 5, pp. 695-697, 1986.

[69] P. J. Baker, R. T. Evans, and D. C. Roopenian, "Oral infection with Porphyromonas gingivalis and induced alveolar bone loss in immuncompetent and severe combined immunodeficient mice," Archives of Oral Biology, vol. 39, no. 12, pp. 1035-1040, 1994.

[70] D. L. Pierce, SO. I. Nishiyama, S. Liang et al., "Host adhesive activities and virulence of novel fimbrial proteins of Porphyromonas gingivalis," Infection and Immunity, vol. 77, no. 8, pp. 3294-3301, 2009.

[71] E. A. Novak, H. Shao, C. A. Daep, and D. R. Demuth, "Autoinducer-2 and QseC control biofilm formation and in vivo virulence of Aggregatibacter actinomycetemcomitans," Infection and Immunity, vol. 78, no. 7, pp. 2919-2926, 2010.

[72] D. Polak, A. Wilensky, L. Shapira et al., "Mouse model of experimental periodontitis induced by Porphyromonas gingivalis Fusobacterium nucleatum infection: bone loss and host response," Journal of Clinical Periodontology, vol. 36, no. 5, pp. 406-410, 2009.

[73] D. F. Kinane and G. Hajishengallis, "Polymicrobial infections, biofilms, and beyond," Journal of Clinical Periodontology, vol. 36, no. 5, pp. 404-405, 2009.

[74] D. T. Graves, D. Fine, Y. T. A. Teng, T. E. Van Dyke, and G. Hajishengallis, "The use of rodent models to investigate hostbacteria interactions related to periodontal diseases," Journal of Clinical Periodontology, vol. 35, no. 2, pp. 89-105, 2008.

[75] W. Beertsen, M. Willenborg, V. Everts et al., "Impaired phagosomal maturation in neutrophils leads to periodontitis in lysosomal-associated membrane protein-2 knockout mice," Journal of Immunology, vol. 180, no. 1, pp. 475-482, 2008.

[76] H. S. Oz, T. Chen, W. J. S. De Villiers, and C. J. McClain, "Metallothionein overexpression does not protect against inflammatory bowel disease in a murine colitis model," Medical Science Monitor, vol. 11, no. 3, pp. BR69-BR73, 2005.

[77] H. S. Oz, T. S. Chen, C. J. McClain, and W. J. S. De Villiers, "Antioxidants as novel therapy in a murine model of colitis," Journal of Nutritional Biochemistry, vol. 16, no. 5, pp. 297304, 2005.
[78] H. S. Oz, T. S. Chen, and H. Nagasawa, "Comparative efficacies of 2 cysteine prodrugs and a glutathione delivery agent in a colitis model," Translational Research, vol. 150, no. 2, pp. 122-129, 2007.

[79] H. S. Oz and J. L. Ebersole, "Application of prodrugs to inflammatory diseases of the gut," Molecules, vol. 13, no. 2, pp. 452-474, 2008.

[80] A. García-Lafuente, M. Antolín, F. Guarner et al., "Incrimination of anaerobic bacteria in the induction of experimental colitis," American Journal of Physiology, vol. 272, no. 1, pp. G10-G15, 1997.

[81] T. Ohkawara, J. Nishihira, H. Takeda et al., "Amelioration of dextran sulfate sodium-induced colitis by anti-macrophage migration inhibitory factor antibody in mice," Gastroenterology, vol. 123, no. 1, pp. 256-270, 2002.

[82] H.-S. Kim and A. Berstad, "Experimental colitis in animal models," Scandinavian Journal of Gastroenterology, vol. 27, no. 7, pp. 529-537, 1992.

[83] S. Fiorucci, A. Mencarelli, B. Palazzetti et al., "Importance of innate immunity and collagen binding integrin $\alpha 1 \beta 1$ in TNBS-induced colitis," Immunity, vol. 17, no. 6, pp. 769-780, 2002.

[84] P. F. Liu, S. K. Haake, R. L. Gallo, and C. M. Huang, "A novel vaccine targeting Fusobacterium nucleatum against abscesses and halitosis," Vaccine, vol. 27, no. 10, pp. 1589-1595, 2009.

[85] L. Kesavalu, J. L. Ebersole, R. L. Machen, and S. C. Holt, "Porphyromonas gingivalis-virulence in mice: induction of immunity to bacterial components," Infection and Immunity, vol. 60, no. 4, pp. 1455-1464, 1992.

[86] L. Kesavalu, S. C. Holt, and J. L. Ebersole, "Trypsin-like protease activity of Porphyromonas gingivalisas a potential virulence factor in a murine lesion model," Microbial Pathogenesis, vol. 20, no. 1, pp. 1-10, 1996.

[87] L. Kesavalu, S. C. Holt, and J. L. Ebersole, "Porphyromonas gingivalis virulence in a murine lesion model: effects of immune alterations," Microbial Pathogenesis, vol. 23, no. 6, pp. 317-326, 1997.

[88] L. Kesavalu, S. C. Holt, and J. L. Ebersole, "Virulence of a polymicrobic complex, Treponema denticola and Porphyromonas gingivalis, in a murine model," Oral Microbiology and Immunology, vol. 13, no. 6, pp. 373-377, 1998.

[89] F. Feuille, J. L. Ebersole, L. Kesavalu, M. J. Steffen, and S. C. Holt, "Mixed infection with Porphyromonas gingivalis and Fusobacterium nucleatum in a murine lesion model: potential synergistic effects on virulence," Infection and Immunity, vol. 64, no. 6, pp. 2095-2100, 1996.

[90] P. B. Chen, L. B. Davern, J. Katz, J. H. Eldridge, and S. M. Michalek, "Host responses induced by co-infection with Porphyromonas gingivalis and Actinobacillus actinomycetemcomitans in a murine model," Oral Microbiology and Immunology, vol. 11, no. 4, pp. 274-281, 1996.

[91] T. Kuriyama, K. Nakagawa, S. Kawashiri, E. Yamamoto, S. Nakamura, and T. Karasawa, "The virulence of mixed infection with Streptococcus constellatus and Fusobacterium nucleatum in a murine orofacial infection model," Microbes and Infection, vol. 2, no. 12, pp. 1425-1430, 2000.

[92] M. Yoshimura, N. Ohara, Y. Kondo et al., "Proteome analysis of Porphyromonas gingivalis cells placed in a subcutaneous chamber of mice," Oral Microbiology and Immunology, vol. 23, no. 5, pp. 413-418, 2008.

[93] J. Anthony, C. Waldner, C. Grier, and A. R. Laycock, "A survey of equine oral pathology," Journal of Veterinary Dentistry, vol. 27, no. 1, pp. 12-15, 2010. 
[94] K. L. Tyrrell, D. M. Citron, J. R. Jenkins et al., "Periodontal bacteria in rabbit mandibular and maxillary abscesses," Journal of Clinical Microbiology, vol. 40, no. 3, pp. 1044-1047, 2002.

[95] D. A. W. Oortgiesen, G. J. Meijer, A. L. J. J. Bronckers, X. F. Walboomers, and J. A. Jansen, "Fenestration defects in the rabbit jaw: an inadequate model for studying periodontal regeneration," Tissue Engineering C, vol. 16, no. 1, pp. 133140, 2010.

[96] J. King and A. Gimson, "Experimental investigations of parodontal disease in the ferret and related lesions in man," British Dental Journal, vol. 83, pp. 126-127, 1947.

[97] M. A. Weinberg and M. Bral, "Laboratory animal models in periodontology," Journal of Clinical Periodontology, vol. 26, no. 6, pp. 335-340, 1999.

[98] R. Baron and J. L. Saffar, "A quantitative study of bone remodeling during experimental periodontal disease in the golden hamster," Journal of Periodontal Research, vol. 13, no. 4, pp. 309-315, 1978.

[99] W. A. Miller and J. F. Ripley, "Early periodontal disease in the Syrian hamster," Journal of Periodontology, vol. 46, no. 6, pp. 368-374, 1975.

[100] K. Hojo, A. Tamura, C. Mizoguchi, D. Kato, T. Ohshima, and N. Maeda, "Predominant bacteria recovered from a periodontitis site in a hamster model raised by silk-ligature with Prophyromonas gingivalis infection," Bioscience, Biotechnology and Biochemistry, vol. 72, no. 5, pp. 1348-1351, 2008.

[101] Y.-K. Chen and L.-M. Lin, "DMBA-induced hamster buccal pouch carcinoma and VX2-induced rabbit cancer as a model for human oral carcinogenesis," Expert Review of Anticancer Therapy, vol. 10, no. 9, pp. 1485-1496, 2010. 


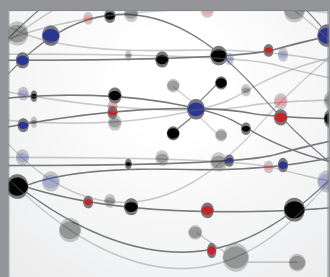

The Scientific World Journal
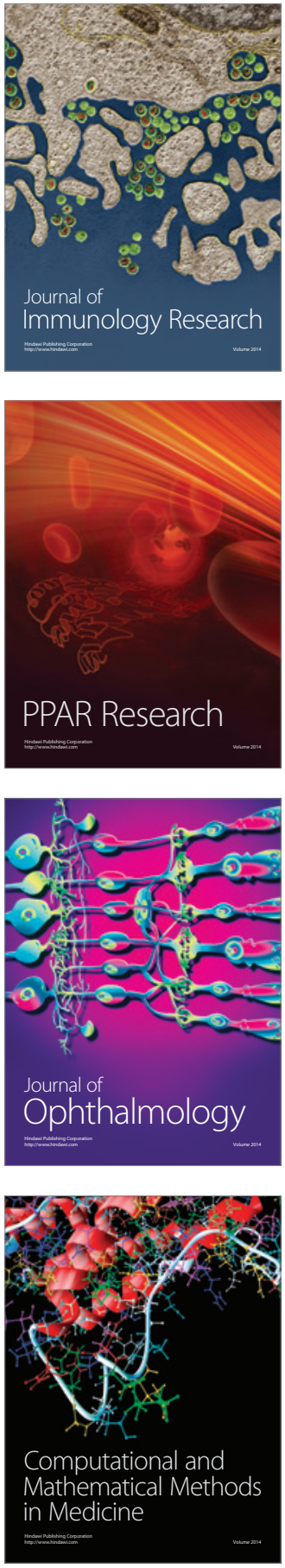

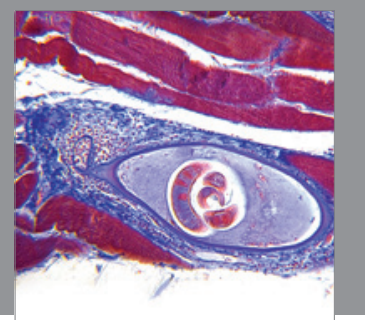

Gastroenterology

Research and Practice
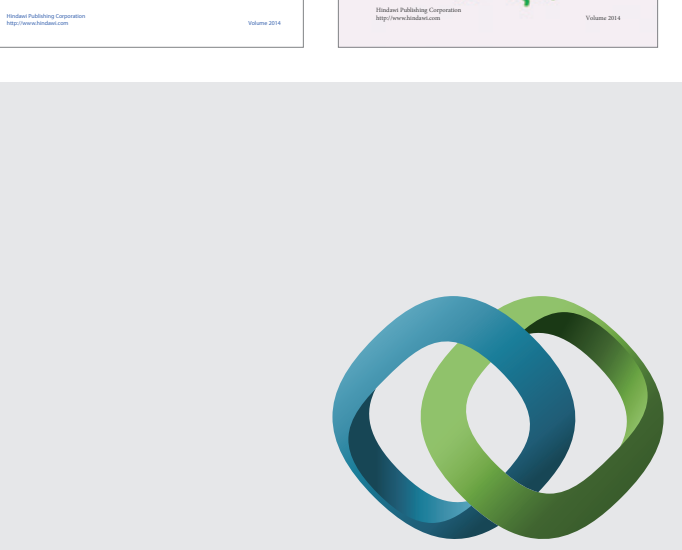

\section{Hindawi}

Submit your manuscripts at

http://www.hindawi.com
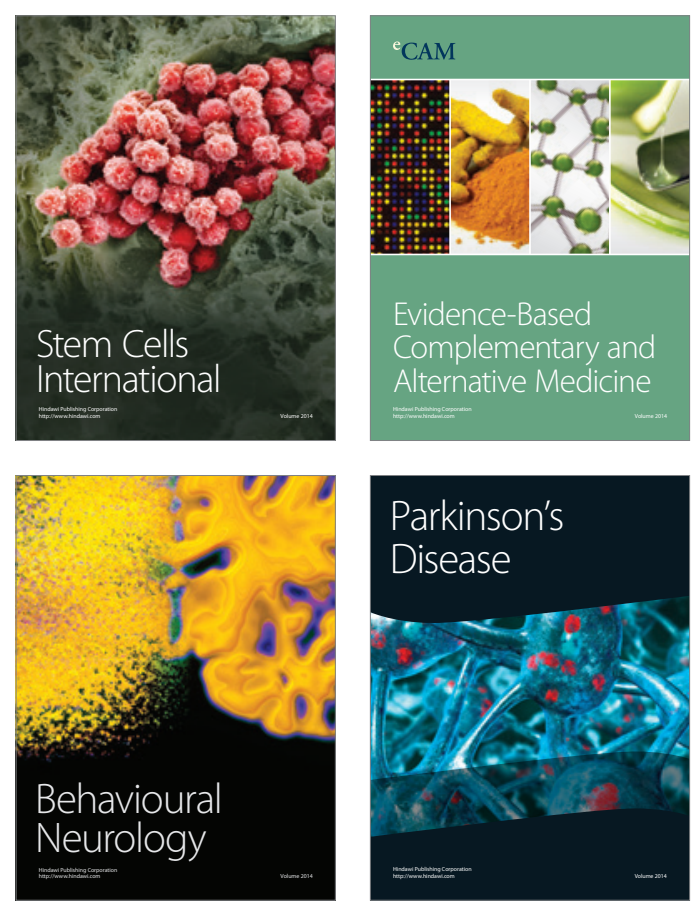

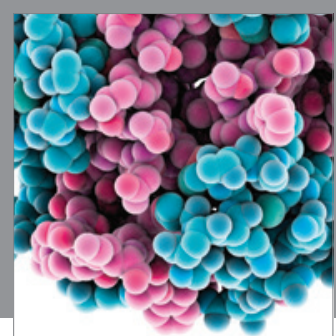

Journal of
Diabetes Research

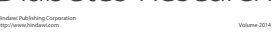

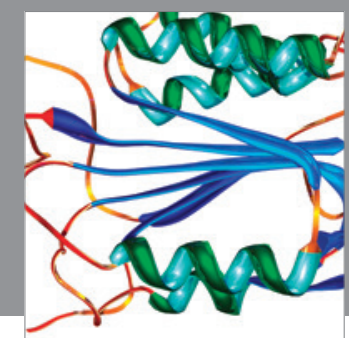

Disease Markers
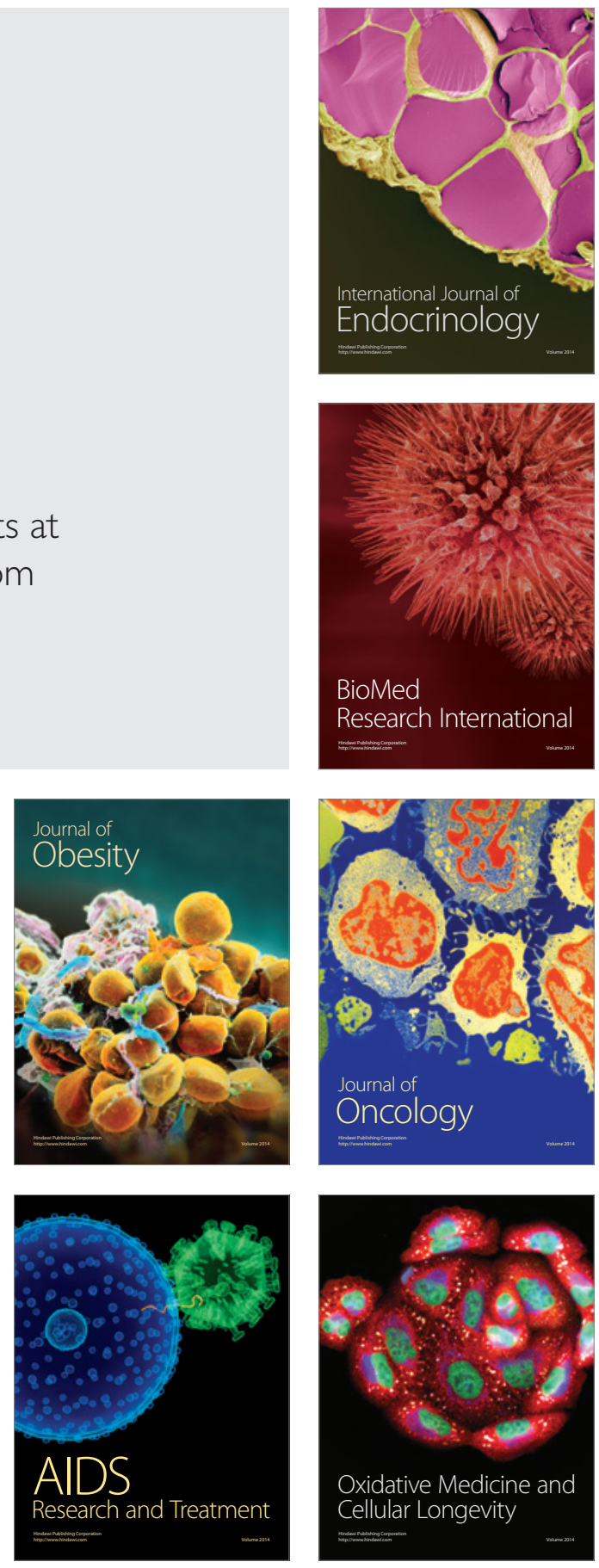